surgery. Their unique experience would then be available to the Commission and to psychiatrists wishing to refer patients for psychosurgery locally. Of course, the opinions of other appropriate commissioners would be obtained as needed. There may be protestations that the Commission must remain totally independent. But if specially experienced doctors cannot be trusted, substitution by lawyers and multiprofessional committees is a most unsatisfactory clinical alternative.
REFERENCES

'BRIDGES, P. K. (1983) ‘ . . and a small dose of an antidepressant might help'. British Journal of Psychiatry, 142, 626-8.

${ }^{2}$ GoKTEPE, E. O., YounG, L. B. \& BRIDGES, P. K. (1975) A further review of the results of stereotactic subcaudate tractotomy. British Journal of Psychiatry, 126, 270-80.

3Evans, B., Bridges, P. K. \& Bartlett, J. R. (1981) Electroencephalographic changes as prognostic indicators after psychosurgery. Journal of Neurology, Neurosurgery and Psychiatry, 44, 444-7.

\title{
Compulsory Treatment in the Community: Is it Authorized under the Mental Health Act 1983 ?
}

\author{
Peter Rohde, Consultant Psychiatrist, St Mary Abbots Hospital, London W8
}

The Mental Health Act 1983 stimulated discussion on all aspects of compulsion in psychiatry. It has been the practice at St. Mary Abbots Hospital to use the powers granted by Section 39 of the 1959 Act and Section 17 of the 1983 Act as a means of compelling a small number of seriously ill patients to take medicines in the community, and I described this practice briefly in a recent article.'

Lydia Sinclair, Legal Officer for MIND, in a long and detailed letter, ${ }^{2}$ critizes this practice:

The purpose of Section 3 (old Section 26), admission for treatment, is to admit to hospital and detain for the period allowed. The procedure and criteria for admission are clearly stated in the Act, detention in hospital and in-patient treatment are intended. Leave of absence under Section 17 of the Act is to be given for temporary absence, a specific occasion, or a period of trial of the patient's suitability for discharge (memorandum to the Act). The Act does not authorize leave of absence to be used indefinitely as a means of enabling medicines to be given under a detention order, or to facilitate the patient's quick return to hospital under the recall provisions of Section 17 (4).

Unfortunately, the British Medical Journal were unable to publish my reply for reasons of space and because 'the correspondence is now above the heads of most of our readers'. This issue deserves further airing and clarification in the proposed Code of Practice to be issued by the Mental Health Commission.

The clinical problem can by briefly stated. How do we treat the small group of seriously ill patients who remain well only if they take treatment in the community, yet refuse to take that treatment? In practice, that treatment is, virtually always, medicines. By definition, these patients relapse if they do not take the treatment; therefore, the real alternatives to compulsory treatment in the community are deterioration in the mental state, or compulsory treatment as an in-patient. The bone of contention between myself and MIND's legal officer is whether compulsory treatment is lawful under the present Act and, if so, under which Section. Does the wording of the Act and its Memorandum justify Mrs Sinclair's statement? The 1983 Act says (Section 17):

1. The responsible medical officer may grant to any patient who is for the time being liable to be detained in a hospital under this part of the Act, leave to be absent from the hospital subject to such conditions (if any) that the Officer considers necessary in the interests of the patient or for the protection of other persons.

Leave of absence may be granted to a patient under this Section either indefinitely or on specified occasions, or for any specified period. Where leave is so granted for a specified period, that period may be extended by further leave granted in the absence of the patient.

Note that the Act specifically states that the responsible medical officer can make conditions and grant leave indefinitely. This appears to me to justify medicines in the community on a long-term basis ('conditions' and 'indefinitely'). Mrs Sinclair quotes the Memorandum of the Act in support of her contention that the Act does not authorize leave of absence to be used indefinitely. The relevant Section, Paragraph 72 of the Memorandum, says: 'Leave of absence can be given either for a temporary absence or on a specific occasion after which a patient is expected to return to hospital, or as a period of trial of the patient's suitability for discharge.' It is certainly true that the Memorandum omits the word 'indefinitely'. However, the Memorandum is not an 'authoritative' interpretation of the law, this is specifically disclaimed in Paragraph 2 of the Memorandum itself. The implication therefore is that where there is conflict we should prefer the Act itself to the Memorandum.

The wording of the relevant sections on leave in the 1959 Act (Paragraph 39) and the 1983 Act (Paragraph 17) is identical, so that any discussions that may have taken place concerning the 1959 Act are relevant. The Royal Commission on the law relating to mental illness and mental 
deficiency, 1954-57, reported in 1957 (the Percy Report) and this resulted in the Mental Health Act of 1959. The Report discussed this problem in some detail (see Paragraphs 306, 477 and 673-678). They recommended:

Para 477 (a): A patient who has been the subject of compulsory powers in hospital after admission under the 'main procedures' should be able to leave hospital at any time for any purpose with the approval of the Medical Superintendent without the compulsory powers being terminated or transferred... The Medical Superintendent should be able to make any condition he considers necessary as to the patient's care and his place of resisdence or employment while absent from the hospital... The Medical Superintendent should have the power to re-admit or recall the patient to hospital at any time within a period of six months after leaving hospital, without going through the procedure for a new compulsory admission. It should be possible for the compulsory powers to be renewed by the normal renewal procedure if otherwise due to expire during the six-month period. 477 (b): When these arrangements are used to send a patient out of hospital on trial for discharge, his day to day care should be taken over by the Local Health Authority as soon as convenient, usually well before the end of the six-month period. At any time within that period the compulsory powers may be terminated by discharge from hospital care or may be transferred into guardianship.

Later, in discussing their view that the after-care of patients is something that the Local Authority should be responsible for, but that compulsion should be provided for if necessary, they clearly imply guardianship should be used to take over this power on behalf of the Local Authority from the hospital order.

Para 676 It should be the duty of the Local Authority to provide after-care for all patients who need it. This should apply to all patients who require such care, whether they be subject to compulsory powers or not ... If the patient has been subject to compulsory powers while in hospital and if proper after-care cannot be provided without continuation of such powers, the patient should be transferred to guardianship, not more than six months after leaving hospital.

The pattern intended by the Percy Commission is clear.

The Report of the Committee on Mentally Abnormal Offenders (the Butler Report) ${ }^{3}$ discussed the question of discharge from hospital of patients who have been treated compulsorily in hospital, quoting the paragraphs from the Percy Report with approval, and indicate that these powers existed under the 1959 Act.

Arrangements on these lines seem to us to be very sensible and we hope that in future home leave will be more widely used as a prelude to discharge or as a stage in the process of discharge. [Para 7.3]

They go on, however, to comment on the practice of extending leave beyond six months:
We have noted that the six-month limit provided for under Section 39 is sometimes avoided by recalling the patient to hospital for a few days near the end of the six months and then sending him out on a fresh period of leave. While this practice can be defended on the ground that the patient's progress ought to be assessed by doctors before he is discharged and that he will be discharged as soon as the doctors are satisfied, we think that the renewal of the hospital's hold over the patient is difficult to justify where the patient has been living satisfactorily in the Community for nearly six months.

Larry Gostin, Legal and Welfare Officer for MIND, writing in 1977,4 says:

The Butler Committee was right to emphasize the existing authority of doctors to grant a leave of absence. Indeed, Section 39 should be used much more by the Medical Profession, both for hospital order patients and for those detained under Part IV of the Act.

Gostin's advocacy of more use of trial is particularly interesting in contrast with Mrs Sinclair's, since he has only recently left MIND's Legal Department.

Edwards, writing on 'leave of absence', further supports the use of leave for treatment:"

Normally however, leave of absence is intrinsically part of the treatment required and is as a rule a clinical measure within medical prescription. The Act regulates the conditions under which the patient is detained to allow medical treatment and the liberty of the patient is protected by Section 39 and Section 43 relating to his right to apply to the Mental Health Review Tribunal if the period of detention is renewed.

The conclusion, therefore, is that compulsory after-care was recognized as necessary by the Percy Commission and it was meant to be provided by the hospital for up to six months after which it was to be transferred to guardianship and that the 1959 Act was phrased accordingly. However, things did not work out. The document $A$ Review of the Mental Health Act $^{6}$ notes:

Para 5.3: Under the present legislation guardianship provides the only effective form of control for those mentally disordered adults in the Community for whom some form of compulsory powers are required over a substantial period of time.

But the authors of the report are clearly puzzled at the extremely low use of guardianship for the mentally ill. Their figures quoted in Appendix $\mathrm{V}$ suggest that at no time between 1960 and 1974 were there more than 24 mentally ill persons subject to guardianship in England.

The White Paper, Review of the Mental Health Act 1959.' discusses the pros and cons of compulsory care in the community in chapter 4, but comes to no clear conclusion. Perhaps for this reason, the 1983 Act, when it emerged, has exactly the same wording on the subject of leave of absence as has the 1959 Act. The guardianship provisions, however, 
are revised so that among the effects of guardianship are (Section 8(b)) to give the Guardian 'the power to require the patient to attend at places and times so specified for the purpose of medical treatment, occupation, education or training.'

What does all this mean? The wording, with the implication that the patient is brought to a place of treatment, is at least as strong, if not stronger than that used in the 1959 Act concerning the effects of admission for treatment which appears to be the sole authority in that Act to give treatment against the patient's wishes.

Para 31 (I): An application for the admission of a patient to a hospital under this part of the Act ... shall be sufficient authority for the applicant... to take the patient and convey him to hospital and convey him at any time within the following period...

Para 31 (ii): The application shall be sufficient authority for the Manager to detain the patient in accordance with the Act

These words seem to have been taken as sufficient authority to give a patient treatment against his will for the past 24 years. I therefore wonder if the re-wording of the guardianship provision was actually intended to strengthen guardianship to the point that medical treatment could be imposed upon the patient in the community. It might perhaps have been hailed as allowing this but for Paragraph 45 of the Memorandum to the Act which states: 'The Guardian does have the powers to require the patient to attend for medical treatment (but not to make him accept treatment).'

We must remember that the Memorandum does not have the force of law and is not infallible (see Note 1).

If the role of guardianship is to be reassessed it is necessary to try and answer the question of why it has been so little used when the Percy Commission regarded it as an important element in after-care.

Between 1960 and 1974 the highest use of guardianship was 1974 when there were 24 cases in England. ${ }^{6}$ In 1973, 17 patients were sent into the community on trial under Section 39 from St Mary Abbotts Hospital, one DGH unit of $\mathbf{4 0}$ beds. The contrast is so striking that it requires explanation. I submit that the difficulty is that guardianship puts the responsibility and power in the hands of the Local Authority social workers, while the power and responsibility to prescribe medicines is in the hands of an NHS doctor. The development that the Percy Commission could not have foreseen was the major tranquillizers. These drugs only came into general usage after the Commission reported and the advantages of maintenance treatment in preventing relapse remained to be proved for a decade or so. ${ }^{8}$ The fact that effective anti-psychotic medicines could be given at monthly intervals would have seemed like a pipe dream to the Percy Commission, yet this was established by the early 70s.' Reading the present Act and Memorandum together, it is far from clear whether the new Act recognizes these new developments or not.

\section{Conclusions}

The present Act allows medical treatment in the community for up to six months (Section 17) and this use of leave provisions was intended by the Royal Commission in 1957 and has been commended by the Butler Committee and the past Legal Adviser of MIND. The Royal Commission envisaged continuing compulsory power where needed for a small minority of patients in the community and they visualized this care being transferred to the Local Authority within six months and continued by guardianship. In practice the leave powers have been used but not the guardianship. The practice of admitting patients for a few days near the end of their six months' leave and then de facto renewing leave for a further six months appears technically possible under the Act, but was clearly not the intention of the Percy Committee. It has the advantage that compliance with treatment is relatively easy to enforce since the patient can be recalled to hospital if not accepting medicine.

It is self evident that a person having compulsory medicine in the community is in a less restrictive setting than a patient receiving the same medical treatment, but being detained as an in-patient at the same time. The effect of guardianship remains unclear.

\section{Recommendations}

The Mental Health Act Commission should consider the problems of the patients who require compulsory treatment in the community to keep them in remission and out of hospital. They should consider:

1. Whether it is good practice to place patients on leave under Section 17 to continue the treatment for up to six months after hospitalization.

2. Whether it is good practice to renew such leave by readmitting within six months for a few days and then discharging on further leave.

3. They should also consider whether (despite the Memorandum), Section 8 (1)b gives the guardian the power to insist that the patient receives medical treatment against his wishes.

Should the Commission decide that Section 8 does give this power, but that it is not good practice to renew leave by brief admissions, it appears a logical conclusion that future good practice should consist of a return to the original Percy recommendations that trial leave should give way to guardianship within six months. There should be a further recommendation which acknowledges that the Local Authority Social Work Guardian and the Registered Medical Practitioner with his hospital team, work as a partnership to ensure that the patient takes medicine and other treatment and that they implement appropriate sanctions if he does not comply with these requirements (see Note 2). 
Should the Mental Health Commission decide that point 2 above is not good practice and that guardianship does not convey the right to enforce medical treatment against the patient's wishes, they should recommend that the Mental Health Act 1983 is amended to provide for compulsory community care, including medicines for the small group of psychiatric patients who may be maintained in the community on medicines, but relapse if they discontinue them and refuse to take the treatment on an informal basis.

REFERENCES

'Rohde, P. D. (1983) Mental Health Act Commission and the Code of Practice. British Medical Journal, 287, 1318.

'Sinclair, L. (1984) Mental Health Act and the Code of Practice (letter). British Medical Journal, 288, 149.

${ }^{3}$ Home Office and Department of Health and Social SECURTY (1975) Report of the Committee on Mentally Abnormal Offenders (the Butler Report). Cmnd 6244. London: HMSO.

‘Gostin, L. O. (1977) A Human Condition, Vol II. London: National Association of Mental Health

'EDWArds, A. H. (1975) Mental Health Service, 4th edition. London: Shaw.

'Department of Health and Social Security (1976) A Review of the Mental Health Act 1959. London: HMSO.

1_ (1978) Review of the Mental Health Act 1959. Cmnd 7320. London: HMSO.

'LEFF, J. P. \& WING, J. K. (1971) Trial of maintenance therapy in schizophrenia. British Medical Journal, iii, 599.

${ }^{9} \mathrm{HIRSCH}$, S. R. et al. (1973) Out-patient maintenance of chronic schizophrenic patients with long-acting fluphenazine. British Medical Journal, $i, 633-37$.
Note 1

The Memorandum to the Mental Health Act 1983: The Memorandum (paragraph 2) says that it is for the guidance of all those who would be working with the Act. It goes on to say 'it cannot provide an authoritative interpretation of the law or override the statutory provisions of the Act or regulations nor does it describe every detail of the Act.' Apart from this disclaimer, which makes it clear that ultimately we must go back to the words of the Act itself, the Memorandum is also not infallible as far as wording is concerned. A curious but important example of this concerns the grounds for detention under Sections 2 3, 4 and 5. In each case the Act refers to "his own health or safety or with a view to the protection of others'-the exact wording in connection with others varies slightly between the Sections. The Memorandum, however, in paragraphs 18 and 19 correctly refers to 'health or safety' but in paragraphs 26 and 33, refers to 'health and safety', a small but very significant error.

\section{Note II}

In my experience patients who have major mental illness, but refuse treatment, commonly change their mind and get involved with the rehabilitation programme after they have been given medicine compulsorily for a time. The opposite however does not apply. The major sanction would be either a forcible injection, or return to hospital. In practice return to hospital is the appropriate sanction and has worked well with the present trial leave. However, for patients subject to guardianship it would have the disadvantage of having to use compulsion against a relatively symptom-free but noncomplying patient. This could be justified on the basis that the order was being used to prevent deterioration, but to ensure that this was done, the Commission would need to spell out that it was good practice to do so.

\section{Second College ECT Survey}

The Research Committee of the College plans to carry out a second survey in 1985-this will be five years after the first. Dr John Pippard and Les Ellam's Report Electroconvulsive Therapy in Great Britain, 1980 came to some worrying conclusions and the authors subsequently made some specific recommendations about how practice might be improved. The object of the second survey would be to determine to what extent these recommendations have influenced practice.

We are at present in the process of applying for funding to the DHSS for the project. If the application is successful we would hope to appoint a senior consultant psychiatrist, for a period of two years, to undertake the survey. It is likely that the survey would be based in London. The post cannot be formally advertised until the project is funded, but the Committee would like to hear from any member of the College who might be interested in such a post.

C. P. FreEman

Secretary, Research Committee

\section{Prevention of Psychiatric Morbidity}

The Section for Social and Community Psychiatry has set up a Working Party to consider the role of prevention in the field of morbidity. The Section for Child and Adolescent Psychiatry have nominated a representative, and the Director of the Health Education Council and Professor J. Morris have been invited to join. At its first meeting held on 14 June, it was agreed to write to all Sections and to invite contributions from individual Members and Fellows. If you have any points that you wish the Working Party to consider, please let me know. We would be particularly interested in hearing of any research in progress or service developments in the field of prevention. The Health Education Council have offered to fund a literature search and we may be looking for a suitably qualified individual to carry out this work (possibly at Senior Registrar level).

A. C. Brown

Convener 